\title{
Predicting the Response of a Temperate Forest Ecosystem to Atmospheric $\mathrm{CO}_{2}$ Increase
}

$\mathrm{DOE} / \mathrm{ER} / 60257--7$

DE93 010081

Annual Report 1992-1993

Request for Funds 1993-1994

Department of Energy grant DE-FGO2-84-ER60257

Submitted by

Fakhri A. Bazzaz

Department of Organismic and Evolutionary Biology Harvard University Cambridge, MA 02138

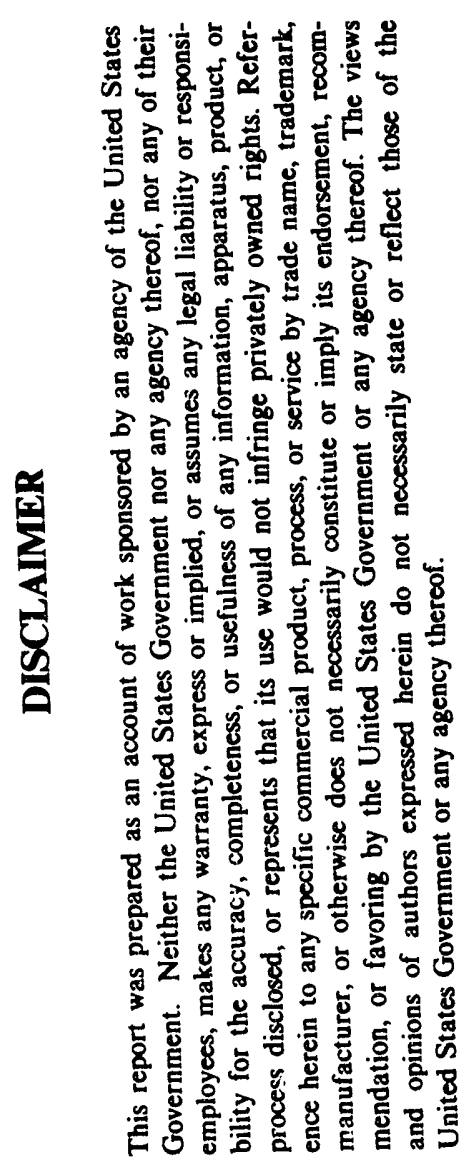

\footnotetext{
$\mathrm{Di}^{\mathrm{i}}$. Roger C. Dahlman

Carbon Dioxide Research Program Department of Energy
} 
1. The reponses of temperate forest tree to 3 years of exposure to elevated $\mathrm{CO}_{2}$, and high and low nutrient and light levels

In this study, six species were grown for three years under different $\mathrm{CO}_{2}$, light, and nutrient conditions. The species used were ash (Fraxinus americana L.), gray birch (Betula populifolia), red maple (Acer rubrum), yellow birch (Betula alleghaniensis), striped maple (Acer pensylvanicum), and red oak (Quercus rubra L.), important tree species of temperate forests in New England, USA. The plants were grown in controlled environments either at 350 or 700 (ambient or elevated) $\mu l l^{-1} \mathrm{CO}_{2}$. The high light treatment (natural light) represented the light condition of a large gap at Harvard Forest $\left(300 \mathrm{~m}^{2}\right)$, whereas the low light treatment (37\% of high light) approximately represented the light condition of the understory. The two nutrient treatments (high and low) simulated high nutrient deposition and organic matter mineralization rates (equivalent to $400 \mathrm{Kg} \mathrm{N} \mathrm{ha}^{-1} \mathrm{yr}^{-1}$ ) and nucrientpoor forest soil at Harvard Forest (equivalent to $40 \mathrm{Kg} \mathrm{N} \mathrm{ha}^{-1} \mathrm{yr}^{-1}$ ), respectively.

Plants growing in elevated $\mathrm{CO}_{2}$ environments were larger than those growing at ambient $\mathrm{CO}_{2}$ after three years (Fig. 4). Two-way analysis of variance $\left(\mathrm{CO}_{2}\right.$ and species) showed that there was a significant $\mathrm{CO}_{2}$ main effect in all three years (in the 1st year $\mathrm{P}<0.0006$, in the 2nd year $\mathrm{P}<0.0009$, and in the 3 rd year $\mathrm{P}<0.0069$ ). Weight ratios (the weight of plants grown in high $\mathrm{CO}_{2}$ divided by that of plants grown in ambient $\mathrm{CO}_{2}$ ) declined for four of the six species after the 1st year (Fig. 5). Only one species (striped maple) showed reduction in weight ratio after two years of increase. The enhancement of plant growth in response to high $\mathrm{CO}_{2}$ levels was highly resource-dependent. Species identity determined whether weight ratio was stable or decreased or increased in the other three resource treatments.

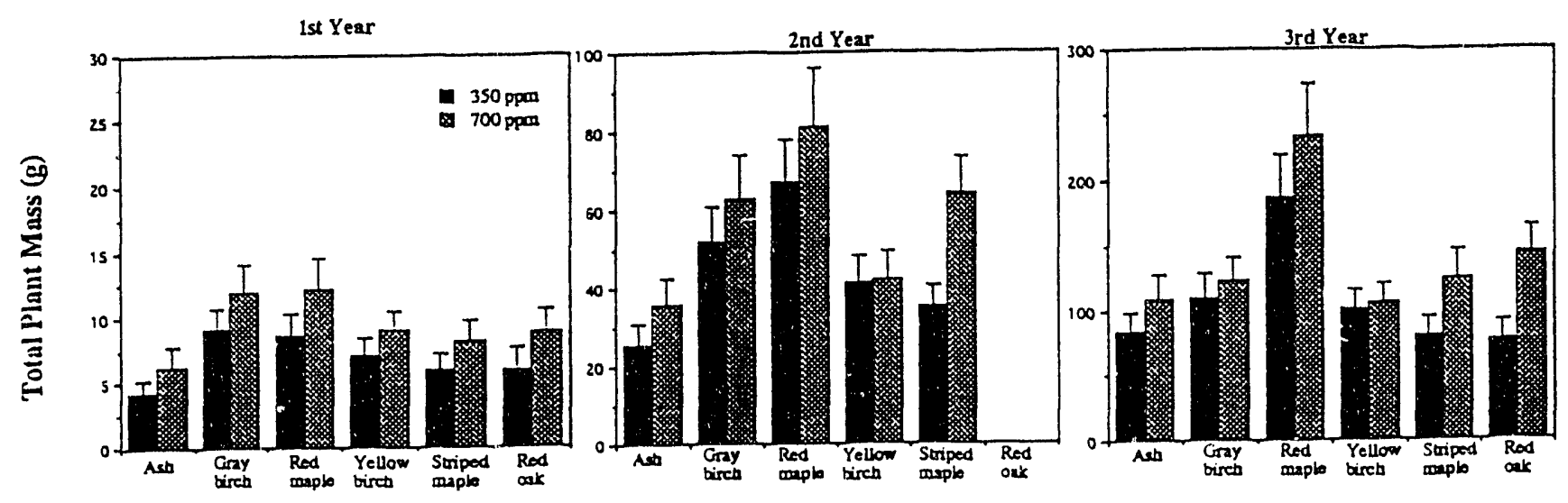

Figure 1. Total plant mass of six temperate tree species grown under various levels of $\mathrm{CO}_{2}$, nutrients and light for three years by pooling various light and nutrient treatments together. Error bars refer to one standard error. 


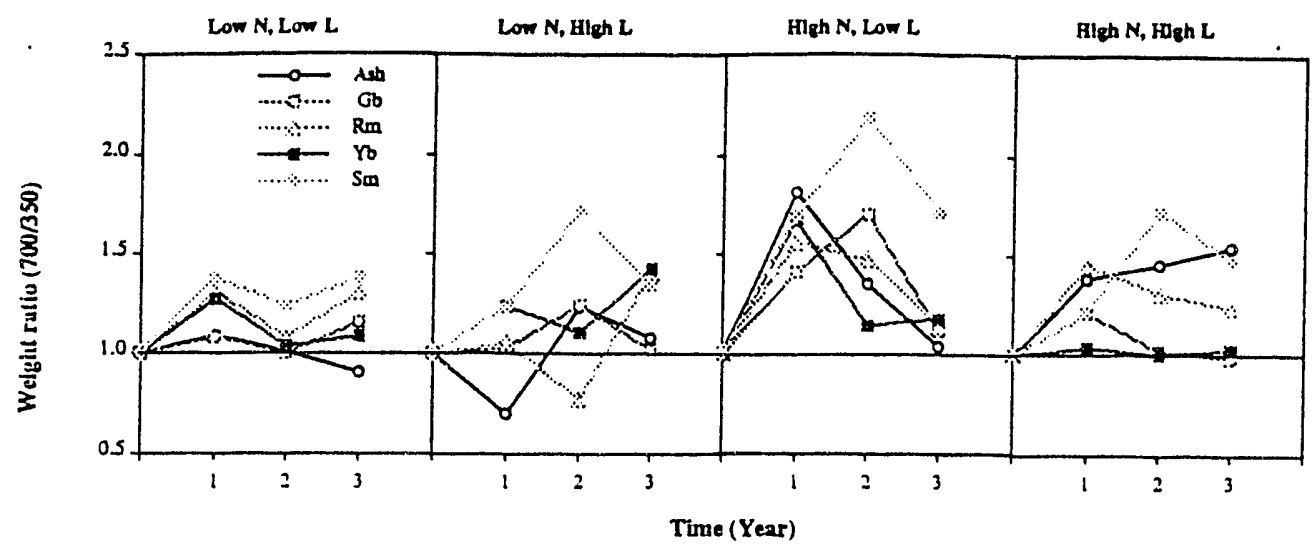

Figure 2. Total weight of plants grown in $700 \mu \mathrm{ll}^{-1} \mathrm{CO}_{2}$ divided by that of plants grown in $350 \mu \mathrm{I} \mathrm{I}^{-1} \mathrm{CO}_{2}$ for three years for five temperate tree species grown in four combinations of light and nutrient levels. "L" and " $N$ " represent light and nutrient levels.

Photosynthesis of fully-developed leaves was measured on plants in each treatment. For each leaf, five measurements were taken at various $\mathrm{CO}_{2}$ levels $(900,700,500,300$, and $100 \pm 20 \mu \mathrm{mol}) . \mathrm{A} / \mathrm{Ci}$ curves were fit to the nonlinear model $\mathrm{A}=\mathrm{A} \infty\left[1-\mathrm{e}^{-\mathrm{k}\left(\mathrm{Ci}-\mathrm{Xo}_{0}\right)}\right]$, where the asymptotic level is the predicted saturated rate of $\mathrm{CO}_{2}$ uptake, $\mathrm{k}$ is the rate of increase in photosynthesis with increase in $\mathrm{CO}_{2}$, and $\mathrm{Xo}$ is the $\mathrm{CO}_{2}$ compensation point. Relative stomatal limitation of photosynthesis (L) was calculated from this data using the formula $\mathrm{L}$ $=(1-(\mathrm{A} / \mathrm{Ao}))^{*} 100$, where $\mathrm{A}$ is the actual Ps value at the ambient concentration of $\mathrm{CO}_{2}$ and $\mathrm{Ao}$ is the $\mathrm{Ps}$ value if the conductance to diffusion of $\mathrm{CO}_{2}$ is infinite (no stomatal limitation). The $\mathrm{CO}_{2}$ response of photosynthesis to intercellular $\mathrm{CO}_{2}$ concentration $(\mathrm{Ci})$ are shown in Fig. 6 for gray birch and red maple plants grown in ambient and elevated $\mathrm{CO}_{2}$, in conjunction with different light and nutrient treatments for three years. Symbols represent the measured data points and lines show the curves fitted to the data for each plant. The $\mathrm{R}_{2}$ value for all curves was above 0.98 for gray birch and 0.95 for red maple. In general, in gray birch long-term exposure to elevated $\mathrm{CO}_{2}$ affected the $\mathrm{CO}_{2}$ response of photosynthesis in one of three ways: (a) the initial slope of the $\mathrm{CO}_{2}$ response decreased, but the predicted $\mathrm{CO}_{2}$-saturated rate of photosynthesis $(\mathrm{A} \infty)$ increased (plants grown in the

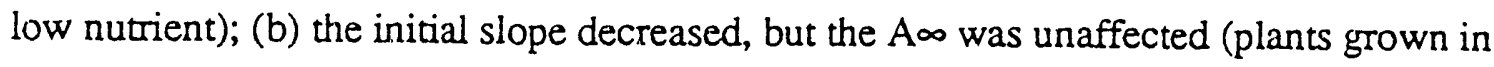
high nutrient and high light); (c) the initial slope was unaffected, but the Ao decreased (plants grown in high nutrient and low light). In contrast, in red maple long-term exposure to elevated $\mathrm{CO}_{2}$ affected the $\mathrm{CO}_{2}$ response of photosynthesis in one of three additional. ways: (a) the initial slope increased, but Ao decreased (plants grown in the high light); (b) the initial slope increased, but $A \infty$ was unaffected (plants grown in the low nutrient and low light); (c) the initial slope was unaffected but $\mathrm{A} \infty$ slightly increased. The transition $\mathrm{Ci}$ 
(Ci where a RuBP-saturated to a RuBP-limited state occurs) in the $\mathrm{CO}_{2}$ response of photosynthesis curves was also affected by long-term exposure to elevated $\mathrm{CO}_{2}$. For plants grown at high $\mathrm{CO}_{2}$, the $\mathrm{ACi}$ curves did not bend off until much higher $\mathrm{Ci}$ levels compared with plants grown in ambient $\mathrm{CO}_{2}$ in gray birch, but there was change in maple.
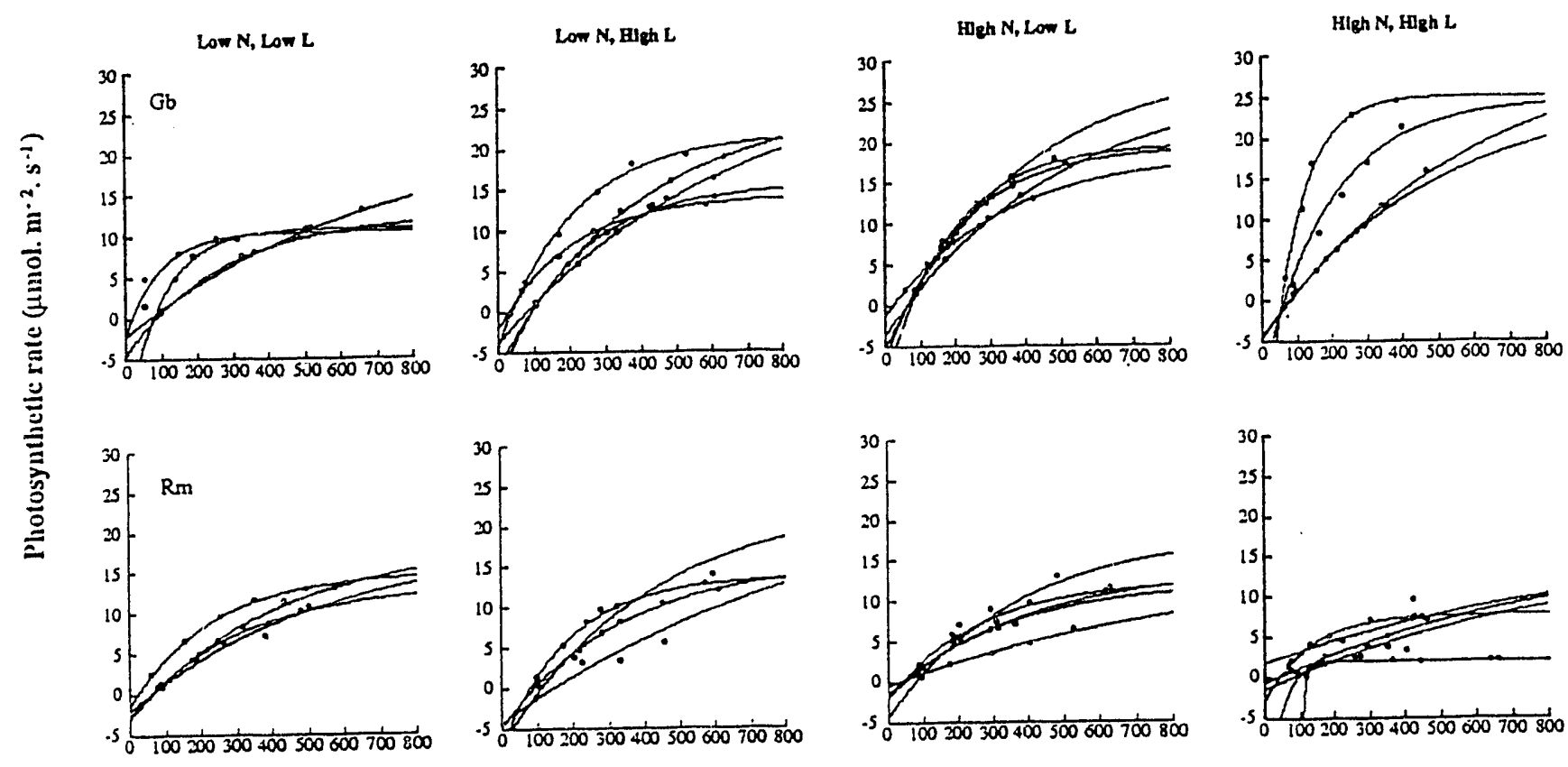

Intercellular $\mathrm{CO}_{2}(\mu \mathrm{mol}$ )

Figure 3. Photosynthesis as a function of intercellular $\mathrm{CO}_{2}$ concentrations for gray birch and red maple plants grown in various levels of $\mathrm{CO}_{2}$, nutrients and light for three years. Each curve was fitted to the nonlinear model: $\left.A=A_{\max }\left(1-e^{-k(C i-X o}\right)\right)$ from five measurements (open circle for $350 \mathrm{ppm}$ plants and closed circle for $700 \mathrm{ppm}$ plants) for one leaf per plant.

\section{Pot-size limitations in $\mathrm{CO}_{2}$ studies}

A second area our research has focused on assessing the extent to which pot size and nutrient availability may influence the degree of $\mathrm{CO}_{2}$ enhancement in our, and other $\mathrm{CO}_{2}$ research. To investigate the relative importance of limited physical rooting space separate from and in conjunction with soil nutrients, we grew plants at ambient and double-ambient $\mathrm{CO}_{2}$ levels in growth containers of varied volumes, shape, nutrient concentration, and total nutrient content. Two species (Abutilon theophrasti, a $C_{3}$ disot with a deep tap root and Setaria faberii, a $\mathrm{C}_{4}$ monocot with a shallow diffuse root system) were selected for their contrasting physiology and root architecture. Shoot demography was determined weekly anci biomass was determined after eight and ten weeks of growth. Increasing total nutrients, either by increasing nutrient concentration or by increasing pot size, increased 
plant growth. Further, increasing pot size while maintaining equal nutrients per pot, resulted in increasing total biomass for both species. But growth and reproductive yield enhancement under elevated $\mathrm{CO}_{2}$ was either unaffected by pot size or was greater in smaller pots (Figure 2). $\mathrm{CO}_{2}$-induced growth enhancement was greatest in pots with high nutrient concentrations, regardless of total nutrient content or pot size, and was also mediated by the shape of the pot.
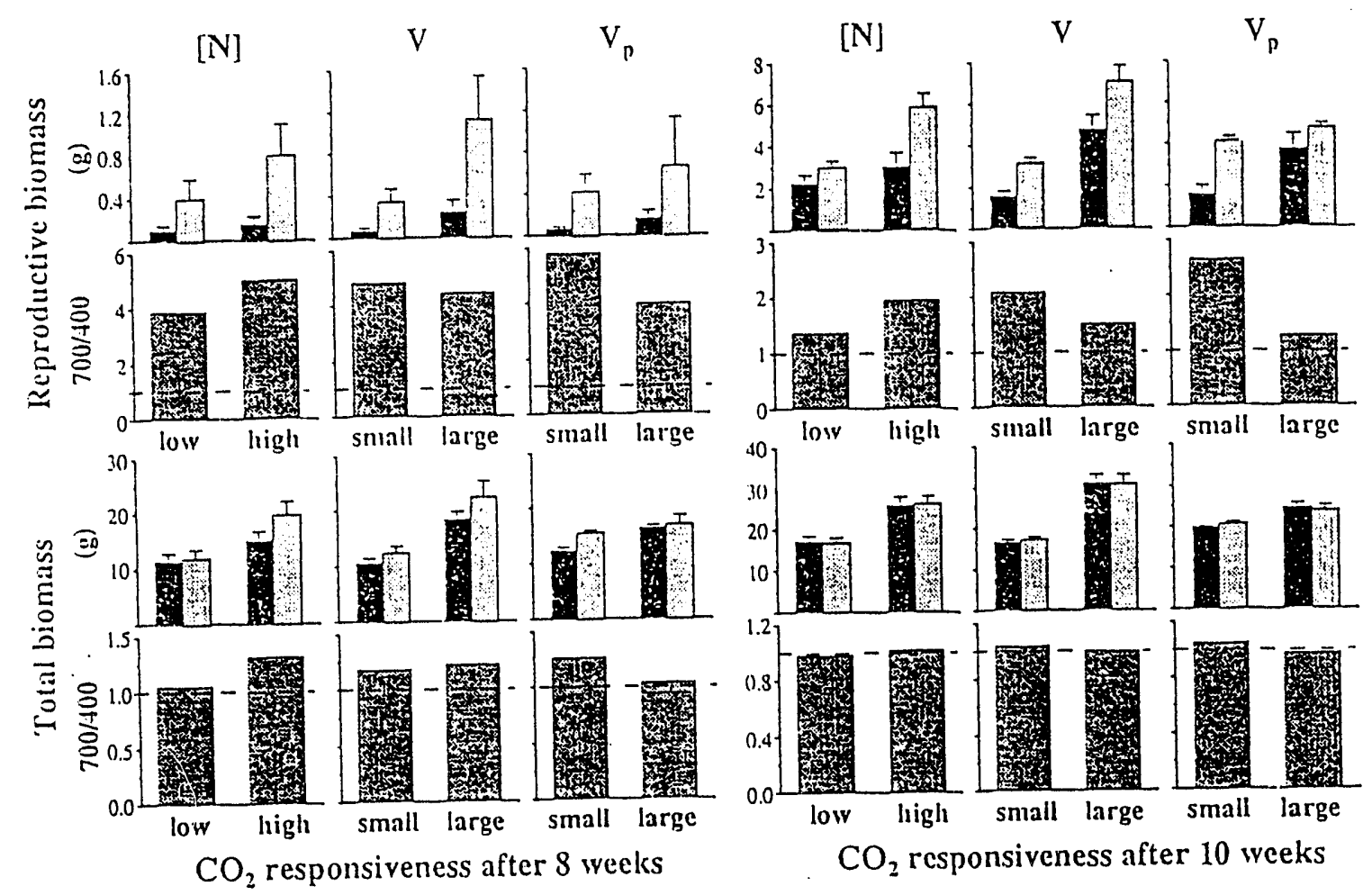

Figure 4. Reproductive and total biomass ( $g+S E$ ) of 8 and 10 week old Abutilon theophrasti seedlings as a function of growth container nutrient content and volume, and $\mathrm{CO} 2$ environment $\left[400 \mu \mathrm{L} \mathrm{L}^{-1}\right.$ (solid bars) or $700 \mu \mathrm{L} \mathrm{L}^{-1}$ (shaded bars)], and enhancement of biomass production due to $\mathrm{CO} 2$ enrichment. The three constrasts displayed represent the effects of 1) doubling total nutrient content per pot by a) doubling nutrient concentration within a constant soil volume ([N]) versus b) doubling soil volume at the same nutrient concentration $(V)$ and of 2 ) doubling growth container (and soil) volume while maintaining the same total nutrient content per pot $\left(\mathrm{V}_{\mathrm{p}}\right)$.

To gain better insight into how elevated $\mathrm{CO}_{2}$ atmospheres affect how plant specifically utilize available below ground space, we also measured patterns of deployment of roots within pots through time. Contrary to aboveground responses, patterns of belowground deployment were most strongly influenced by elevated $\mathrm{CO}_{2}$ in pots of different volume and shape (Fig 3). Further, elevated $\mathrm{CO}_{2}$ conditions interacted differently with limited belowground space for the two species we studied. For Setaria, elevated $\mathrm{CO}_{2}$ increased the size of the largest region of low root density at the pot surface in larger rooting volumes independent of nutrient content, thereby decreasing their efficiency of deployment. For Abutilon, plants responded to elevated $\mathrm{CO}_{2}$ concentrations by equalizing the pattern of 
DOE Annual Report 1992-1993

deployment in all pots. Nutrient concentrations, and not pot size or shape, greatly influenced the density of root growth. Root densities for Abutilon and Setaria were similar to those observed in field conditions, for annual dicots and monocots respectively, suggesting that studies using pots may successfully mimic natural conditions.

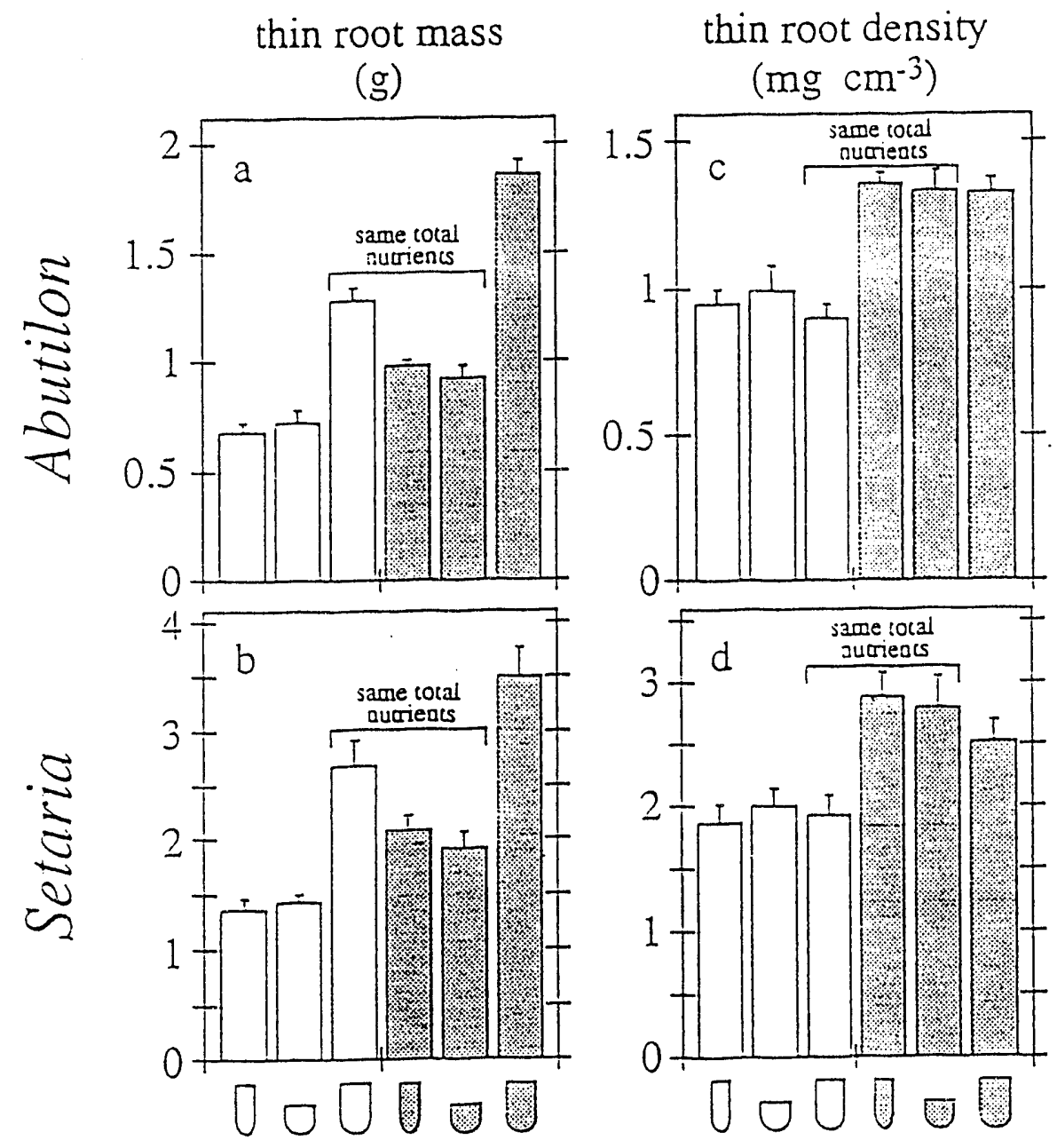

Pot Type

Figure 5. Thin root mass and thin root density for Abutilon and Setaria as a function of pot volume, shape, and nutrient concentration. The three different types of pots are indicated by schematic drawings. The unshaded bars represent the low nutrient concentration $(0.5 \mathrm{~g}$ $\left.\mathrm{L}^{-1}\right)$ and the shaded bars represent the high nutrient concentration $\left(1.0 \mathrm{~g} \mathrm{~L}^{-1}\right)$.

\section{Interactive effects of Carbon Dioxide and Soil Moisture Availability on Tree Seedling's} Tissue Water Relations, Growth, Niche Characteristics.

Our studies of the effects of increasing atmospheric $\mathrm{CO}_{2}$ concentrations and a range soil moisture availabilites on the tissue water relations, growth, and niche characterisitcs of gray birch (Betula populifolia) and red maple (Acer rubrum) seedlings were brought to near completion this year. Components of tissue water relations were estimated from pressure volume curves of trees grown under mesic and xeric water regimes, and either ambient $(350 \mu \mathrm{L} \mathrm{L}-1)$ or elevated $\mathrm{CO}_{2}(700 \mu \mathrm{L} \mathrm{L}$ - 
1). Both $\mathrm{CO}_{2}$ and water treatment had small but significant effects on osmotic potential at full hydration, apoplasmic fractions, and tissue elastic moduli. Under ambient $\mathrm{CO}_{2}$ concentrations, plants showed a decrease in osmotic potentials of $0.15 \mathrm{MPa}$ and an increase in tissue.elastic moduli at full hydration of $1.5 \mathrm{MPa}$ when grown under xeric conditions. The decrease in elasticity may enable plants to improve the soil-plant water potential gradient for a small change in water content while lower osmotic potentials shift the zero turgor loss point to lower water potentials. Under elevated $\mathrm{CO}_{2}$, plants in xeric conditions also had reduced osmotic potentials (0.2 $\mathrm{MPa}$ ) lower than the mesic plants and decreased elastic moduli at full hydration (1.5 MPa). Together these changes at elevated $\mathrm{CO}_{2}$ enabled the xeric plants to maintain positive turgor pressures to lower water potentials and water contents. Surprisingly, the elevated $\mathrm{CO}_{2}$ plants under mesic conditions had the most inelastic tissues. We propose that this inelasticity may enable plants to generate an adequate water potential gradient from the soil to the plant with the low conductances observed under elevated $\mathrm{CO}_{2}$ conditions.

Table 1. Tissue osmotic potential at full hydration $\left(\pi_{\mathrm{i}}\right)$, tissue elastic modulus at full hydration $\left(E_{\mathrm{i}}\right)$, and apoplasmic fraction $\left(\mathrm{R}_{\mathrm{a}}\right)$ for Betula populifolia grown under either mesic or xeric conditions, and either ambient or elevated $\mathrm{CO}_{2}$. Means and standard deviations for three branches.

\begin{tabular}{llll}
\hline $\begin{array}{l}\text { Treatment } \\
350 \mu \mathrm{L} \mathrm{L}^{-1}\end{array}$ & $\pi_{\mathbf{i}}(\mathrm{MPA})$ & $\mathrm{E}_{\mathbf{i}}(\mathrm{MPa})$ & $\mathbf{R}_{\mathbf{a}}$ \\
$\quad \begin{array}{l}\text { mesic } \\
\text { xeric }\end{array}$ & $-0.92(0.01)$ & $4.87(0.57)$ & $0.67(0.02)$ \\
$700 \mu \mathrm{L} \mathrm{L}^{-1}$ & $-1.06(0.01)$ & $6.26(0.77)$ & $0.54(0.02)$ \\
mesic & & & \\
xeric & $-1.03(0.07)$ & $6.81(0.22)$ & $0.61(0.03)$ \\
\hline
\end{tabular}

The second half of this study was designed to determine the effects of elevated $\mathrm{CO}_{2}$ and soil moisture status on growth and niche characteristics of birch and maple seedlings, gray birch (Betula populifolia) and red maple (Acer rubrum) were experimentally raised along a soil moisture gradient ranging from extreme drought to flooded conditions at both ambient and elevated atmospheric $\mathrm{CO}_{2}$ levels. Our results have shown that the magnitude of growth enhancement due to $\mathrm{CO}_{2}$ was largely contingent on soil moisture conditions, but differently so for maple than for birch seedlings. Red maple showed greatest $\mathrm{CO}_{2}$ enhancements under moderately moist soil conditions, whereas gray birch showed greatest enhancements under moderately dry soil conditions (Fig 1). Additionally, $\mathrm{CO}_{2}$ had a relatively greater ameliorating effect in flooded conditions for red maple than for gray birch, whereas the reverse pattern was true for these species under extreme drought conditions. For both species, elevated $\mathrm{CO}_{2}$ resulted in a reduction in niche breadths on the moisture gradient; $5 \%$ for gray birch and $23 \%$ for red maple. Species niche overlap (proportional overall) was also lower at elevated $\mathrm{CO}_{2}(.98$ to $.88: 11 \%)$. This study highlights the utility 
DOE Annual Report 1992-1991

of experiments crossing $\mathrm{CO}_{2}$ levels with gradients of other resources as effective tools for elucidating the potential consequences of elevated $\mathrm{CO}_{2}$ on species distributions and potential interactions in natural communities.

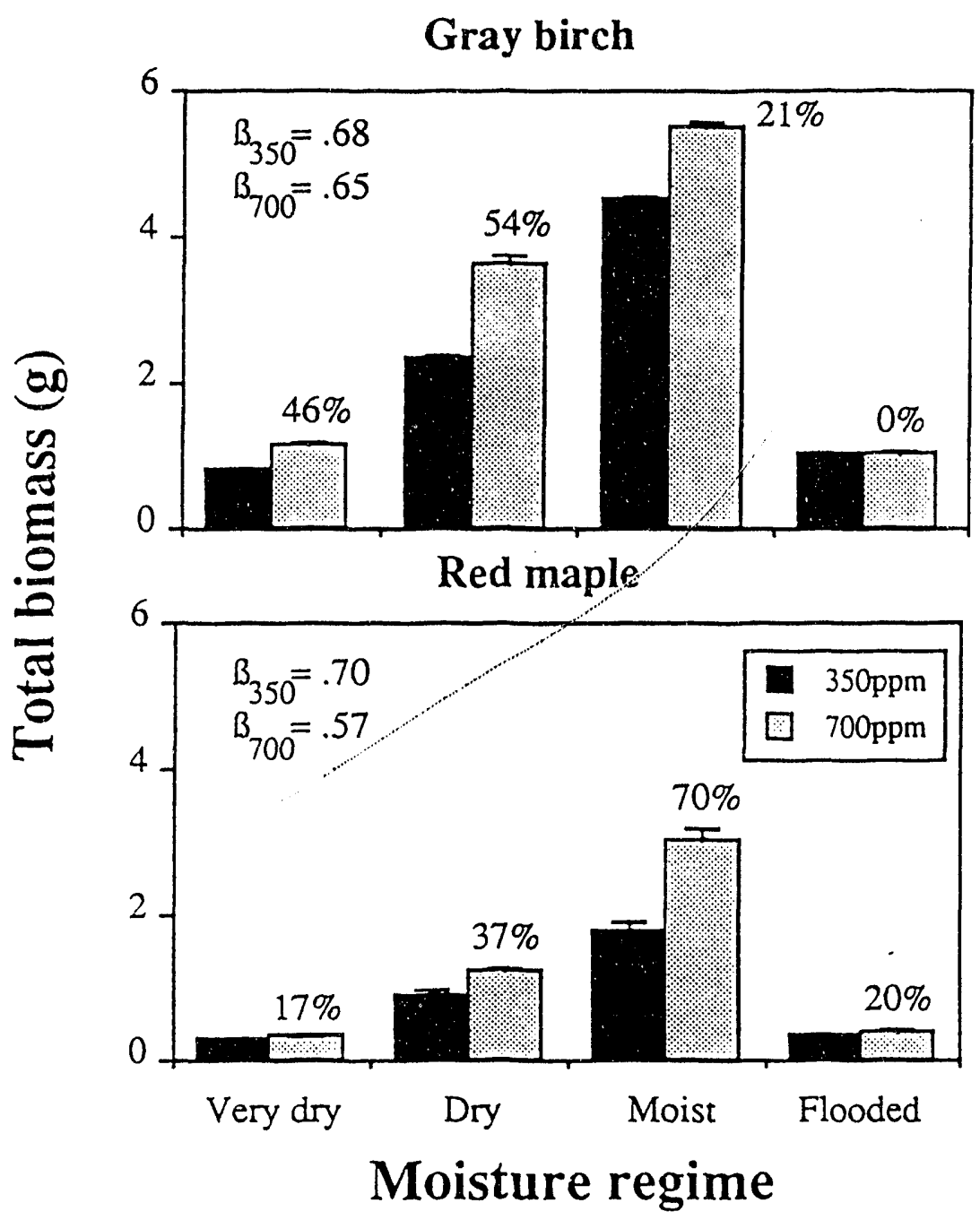

Figure 6. Total biomass of gray birch and red maple grown under various levels of $\mathrm{CO}_{2}$ and moisture. " $B$ " refers to niche breadth (Levins 1968). Numbers on the top of lighter columns represent percent increase in total biomass of plants grown in $700 \mathrm{ppm} \mathrm{CO}_{2}$ relative to plants grown in $350 \mathrm{ppm} \mathrm{CO}_{2}$. Error bars refer to one standard error.

\section{Individual versus population responses to elevated $\mathrm{CO}_{2}$ levels in two species of annual weeds.}

In nature, plants generally grow in the presence of other neighboring plants. While many experiments on the effects of elevated $\mathrm{CO}_{2}$ levels on the growth of individual plants have been conducted, there is little information on the responses of plants grown in dense populations. It may or may not be the case that the growth responses of individual plants are the same as that of the population as a whole. To examine these issues we grew plants of two species of annual weeds (Velvetleaf [Abutilon theophrasti], and Common Dandelion 
[Taraxacum officinale] as individual plants grown in well-spaced pots, and as dense populations grown in flats.

The overall biomass responses to elevated $\mathrm{CO}_{2}$ levels were greater for individual plants than for plants grown at high population densities: for Taraxacum there was even a slight (non-significant) decrease in total biomass at high $\mathrm{CO}_{2}$ for dense populations. These preliminary results strongly suggest that biomass responses predicted on the basis of individual plant responses may not be good a predictor of species responses at the stand level.

\begin{tabular}{llc}
\hline Species & Density & $\begin{array}{c}\text { Proportional increase } \\
\text { in biomass with 2 x CO2 }\end{array}$ \\
\hline $\begin{array}{l}\text { Abutilon } \\
\text { theophrasti }\end{array}$ & High & $+0.013 \%$ \\
& Low & $+0.237 \%$ \\
$\begin{array}{l}\text { Taraxacum } \\
\text { officinale }\end{array}$ & High & $-0.025 \%$ \\
& Low & $+0.449 \%$ \\
\hline
\end{tabular}

We also observed consistent differences in population size structure in response to elevated $\mathrm{CO}_{2}$ levels. Size variability, as measured by the coefficient of variation of total plant biomass, was higher at high $\mathrm{CO}_{2}$ levels than at ambient $\mathrm{CO}_{2}$ levels, this increase being greater for high density populations than individually-grown plants (see fig.7). This results is of particular interest, since size variability is closely associated with variability in reproductive output within plant populations, this being the basis for genetic change through natural selection and drift. We speculate that seive selection processes may operate more strongly in dense populations in nature, and that as global $\mathrm{CO}_{2}$ levels increase, this process will be of particular importance in leading to rapid evolutionary change in plant responses to $\mathrm{CO}_{2}$. 


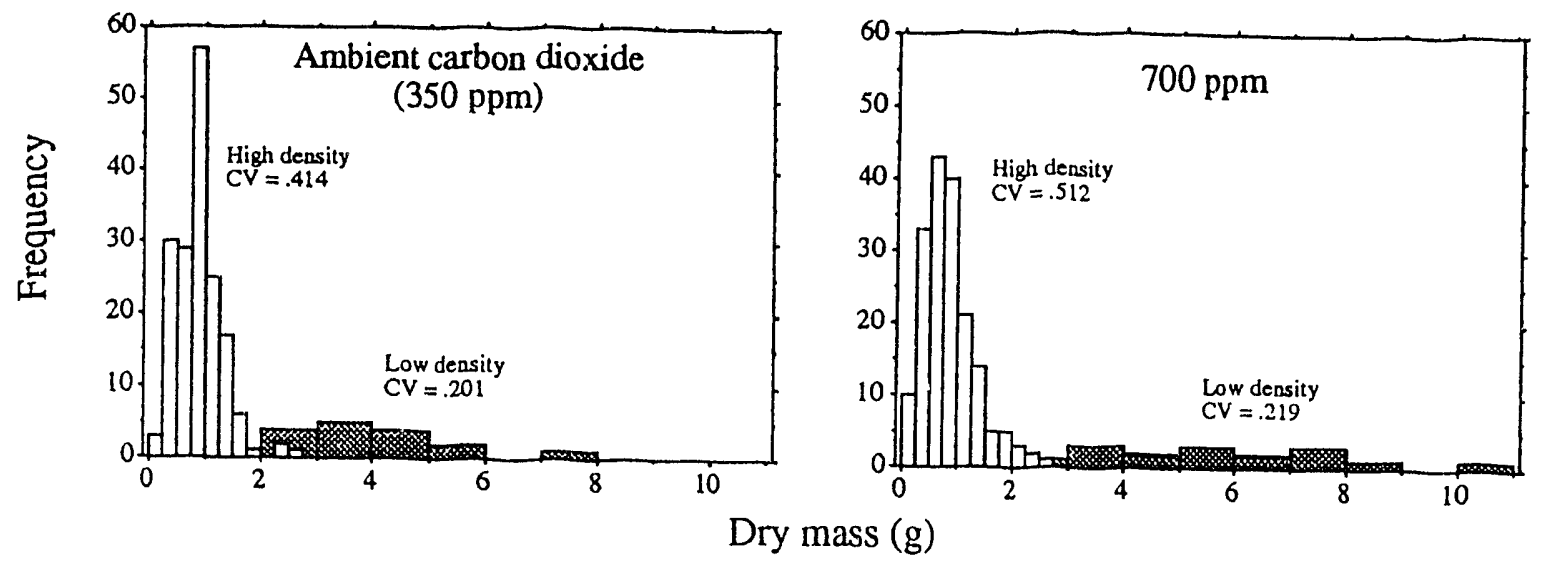

Figure 7. Interactive effects of elevated $\mathrm{CO}_{2}$ and population density on population size structure in the common dandelion (Taraxacum officinale). The increase in size variability with increasing $\mathrm{CO}_{2}$ may lead to rapid evolutionary responses of annual plants to rising $\mathrm{CO}_{2}$ levels (Thomas and Bazzaz, unpublished data).

5. The development of gypsy moth larvae raised on gray and yellow birch foliage grown in ambient and elevated $\mathrm{CO}_{2}$ environments

This study addresses insect-host plant interactions in an elevated $\mathrm{CO}_{2}$ atmosphere. Previous studies we have conducted with herbs have demonstrated that larval performance of Lepidoptera decreases when they are fed leaves of plants grown in elevated $\mathrm{CO}_{2}$ atmospheres. However, little work has been conducted with woody species. It is not known whether closely related host species are affected differently by elevated $\mathrm{CO}_{2}$ in their suitability to insect herbivores. In this study, gypsy moth larvae (Lymantria dispar) were obtained from the USDA facility at Otis Air Force Base and raised on two of their natural host species of New England's temperate forest, yellow and gray birch (Betula alleganiensis and $B$. populifolia). Birch seedlings were germinated and grown at either ambient (350 ppm) or elevated (700 ppm) $\mathrm{CO}_{2}$ in light and temperature controlled chambers. After four months of growth, we placed first instar gypsy moth larvae on these plants. Twenty-four mesh cages, each containing one caterpillar and one plant, were set up for each treatment ( 2 host species $x \geq \mathrm{CO}_{2}$ levels). Over the next two months, larval weights and behavioral measurements were recorded for each of the 96 larvae. We destructively measured a sub sample of plants at the beginning and the end to quantify characteristics that might affect larval performance and to see how they change with time. Meanwhile, other groups of second and third instar larvae were offered choices of leaves. 


\section{( DOE Annual Report $1992-1993$ C}

Three different preference tests were performed in petri dishes: two different (1) species (same $\mathrm{CO}_{2}$, leaf age), (2) $\mathrm{CO}_{2}$ levels (same species, leaf age), or (3) leaf ages (same $\mathrm{CO}_{2}$, species). The data examined so far suggest that larval preference of gypsy moth does change with elevated $\mathrm{CO}_{2}$. Furthermore, larvae grow significantly smaller and reach maturity slower at $700 \mathrm{ppm} \mathrm{CO}_{2}$ and on yellow birch (see Graph 1). Preference data is still being processed, but early results suggest that low $\mathrm{CO}_{2}$ leaves are preferred over high $\mathrm{CO}_{2}$, and yellow birch over gray birch.

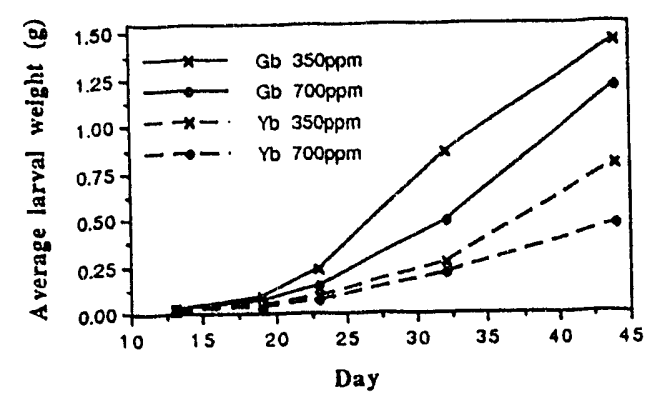

Figure 8. Gypsy moth larval growth as a function of species and $\mathrm{CO}_{2}$ levels. 

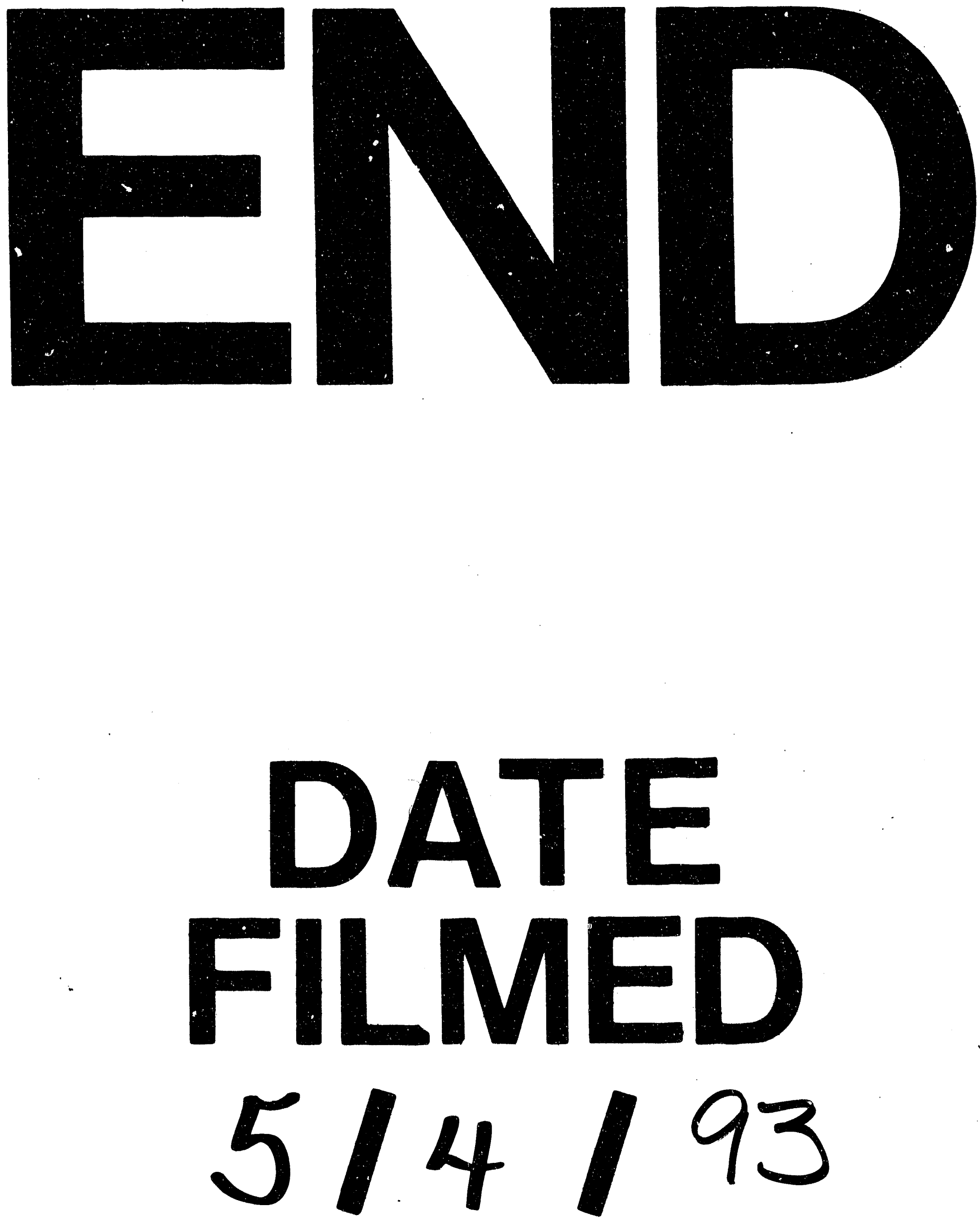